(C) 2022, The Authors. Published by Elsevier Inc. and Fass Inc. on behalf of the American Dairy Science Association ${ }^{\circledR}$. This is an open access article under the CC BY license (http://creativecommons.org/licenses/by/4.0/).

\title{
Transferring a large data library of fresh total mixed rations from a benchtop to 2 portable near-infrared spectrometers for on-farm real-time decisions
}

\author{
Dolores Pérez-Marín, ${ }^{1}$ Begoña de la Roza-Delgado, ${ }^{2}$ J. Antonio Entrenas, ${ }^{1 *}$ Mar Garrido-Cuevas, ${ }^{1}$ \\ and Ana Garrido-Varo' \\ ${ }^{1}$ Faculty of Agriculture and Forestry Engineering (ETSIAM), Universidad de Cordoba, Campus de Rabanales, Carretera de Madrid km. 396, \\ 14071 Cordoba, Spain \\ ${ }^{2}$ Nutrition Research Programme, Regional Institute for Research and Agri-Food Development (SERIDA), PO Box 13, 33300 Villaviciosa, Spain
}

\begin{abstract}
This study was carried out using a spectral database consisting of 394 samples of fresh total mixed ration (TMR) from dairy farms located at Northern Spain. Cloning sets of different size and structure were evaluated for the transfer of the large TMR spectral database obtained on a Foss NIRSystems monochromator to 2 different portable near-infrared devices: one diode array instrument and another based on linear variable filters. The cloning matrix that produced the best matching between instruments was then used to transfer the TMR spectral library to the 2 portable instruments. Once the database had been transferred, calibration equations were developed to compare the predictive ability of the equations obtained in the benchtop and portable instruments. In comparison with the monochromator predictive ability, the calibration equations developed with the near-infrared portable instruments displayed a high and similar accuracy for most of the studied parameters related to TMR composition, enabling their use for predicting TMR quality at the farm level.

Key words: total mixed rations, near infrared (NIR) instrument standardization, on-farm NIR analysis, portable instruments, database transferring
\end{abstract}

\section{INTRODUCTION}

Feeding dairy cows using TMR is not a new practice in livestock production. The earliest full-length article on TMR in the Journal of Dairy Science was published in 1966 (McCoy et al., 1966). Total mixed ration feeding is here to stay, especially as the dairy industry continues to move to larger dairy herds (Schingoethe, 2017). Moreover, the increase of concentrate prices has reinforced even more the use of feed diets based on TMR. James and Cox (2008) suggested that

Received July 19, 2021.

Accepted November 22, 2021.

*Corresponding author: p82enlej@uco.es rising costs of feed ingredients dictate the need for more rigid monitoring of nutrient balances, also termed precision feeding. This makes the role of nutritionists more complex since they must formulate TMR with ingredients (silage, forages, by-products, grains, and so on) that have very high variability in composition. Thus, TMR should be formulated to match cow requirements more closely (i.e., smaller safety factors), which should result in reducing feed costs or increasing milk yields (Weiss and St-Pierre, 2009). Despite the great efforts invested by producers and its advisors (the nutritionists) in closely matching TMR formulation to dairy cow nutritional needs, there are sometimes big differences between the formulated rations and the amount of nutrients ingested by the cow. Small inconsistency of TMR from the nutritional point of view is unavoidable and has many causes and consequences in the health and production of dairy cows (Sova et al., 2014; MillerCushon and DeVries, 2017). It is generally accepted that there are at least 5 rations which can be produced on dairy for the same lot of cows: the ration formulated to meet the cow or the herd requirements; the ration that is entered into the feed management software and calculated using current DM values; the ration that is loaded into the feed wagon; the ration that is delivered to the cows; and the fifth, which is the ration that the cows eat. At each stage of creating the final ration, variation in nutrient content of the ration will increase and be affected by feed management (Kertz, 1998). Examination of the rations fed on 22 commercial freestall farms indicates that producers should be aware about the daily variability in TMR composition and take more proactive measures to ensure that the ration delivered is representative of that formulated by the nutritionist. Measurements to improve TMR composition, in relation to daily variability, may lead to improvements in DMI, milk yield, and efficiency of group-housed dairy cows, ultimately increasing herd profitability (Sova et al., 2014).

Therefore, animal nutritionists are increasingly demanding to have precise information about the major 
chemical constituents of the TMR used to feed high production dairy cows. That will allow them not only to know on site and in real time the quality of the TMR used on a farm, but it will also provide a very useful sensor to better quantify the precision and accuracy of feeding on the farm and the associated implications.

The perspective of the use of near-infrared spectroscopy (NIRS) in precision livestock farming has expanded considerably and has gone, in a very short time, from simple prediction of the chemical composition of raw materials to prediction of chemical and physical composition in mixtures of raw materials or in TMR (Evangelista et al., 2021). The dairy sector has benefited extensively from the pioneering research undertaken by Norris et al. (1976) and Shenk (1977) about the NIRS prediction of the quality of forages. Currently, the NIRS literature consists of hundreds of research articles related to forage near infrared (NIR) analysis. In the beginning these papers were done using dried and finely milled samples (Coelho et al., 1988; Decruyenaere et al., 2009), but later the research was extended to cover wet forages (Park et al., 1998; Sørensen, 2004; Thomson et al., 2018). However, in comparison, the NIRS scientific literature related to TMR is rather limited. Mentink et al. (2006) developed calibrations for 110 TMR samples and concluded that NIRS had utility to predict basic nutrients such as CP, NDF, starch, NFC, and fat. Soldado et al. (2009), using 183 TMR samples, developed calibrations of high accuracy for DM, CP, crude fiber (CF), fat, starch, NDF, and ADF. However, both studies were done using benchtop instruments only able to do at-line analysis in the laboratory. To our knowledge there are no published papers aimed at evaluating the performance of portable instruments for their application to on-farm TMR analysis.

Several portable and on-site NIR instruments have been available since the late 1990s; however, they have mainly been used at the research domain for foods such as fruits and vegetables. By that time, those instruments had some limitations for the widest applicability (Saranwong and Kawano, 2005), such as limited wavelength range (less than 1,100 nm), low resolution, poor reproducibility, limited optical window size, lack of compartment cell for liquids, the need to be connected to an external computer, and so on. However, by the first decade of the 21st century, the advances in handheld and micro NIR instrumentation have been enormous, due to the rapid progress experienced in technologies such as micro-electro-mechanical systems and its integration with micro-optics, linear variable filters, or diode array (Crocombe, 2018; Yan and Siesler, 2018; Beć et al., 2020).
Thus, today, there are several NIRS instruments on the market with characteristics of portability and price that make them suitable to be acquired by individual nutritionists or by analytical services companies, enabling control at the farm level. Some of these instruments are supplied with calibrations for forages and TMR. However, rigorous scientific information is not available about the performance of the new handheld instruments for the prediction of the chemical composition of TMR.

Moreover, as has been happening in the process of moving from the NIR laboratory to the on-line feed processing plant (Fernández-Ahumada et al., 2008), the scientific community should demonstrate that the costly existing databases of TMR samples that some laboratories and research centers have produced for years using high-cost and research-grade at-line NIRS instruments could be moved to portable on-farm NIR analysis, avoiding the need to restart from the beginning.

Therefore, the objective of this research was to evaluate the feasibility of transfer of a large data set of TMR samples analyzed on a benchtop instrument to 2 different portable NIR instruments, together with the evaluation of the equations obtained in the 3 instruments for prediction of the quality of TMR.

\section{MATERIALS AND METHODS}

\section{Samples, Instrumentation, and Spectra Acquisition}

For standardization purposes, 27 TMR samples from farms located in the south and north of Spain and collected in 2018 were analyzed. These were considered representative of the spectral database to be transferred, which consisted of 394 samples corresponding to rations for heifers and cows in the lactation period, composed mostly of cereal silage, dehydrated alfalfa, oat hay, and concentrates. This database was generated at the Regional Institute for Research and Agri-Food Development (SERIDA) Nutrition Laboratory (Asturias, northern Spain) using a Foss NIRSystems 6500 (FSN) NIRS instrument, a benchtop device able to do at-line analysis in the laboratory, working under the requirements of ISO/IEC 17025 (ISO, 2017). All of the samples used in this research consisted of cereal silage, oat hay, and dehydrated alfalfa.

The NIRS analysis of the 27 TMR samples was carried out on the 3 instruments described below.

1. A monochromator, Foss NIRSystems 6500 (FNS; Foss NIRSystems Inc.), equipped with a transport module that operates in the spec- 

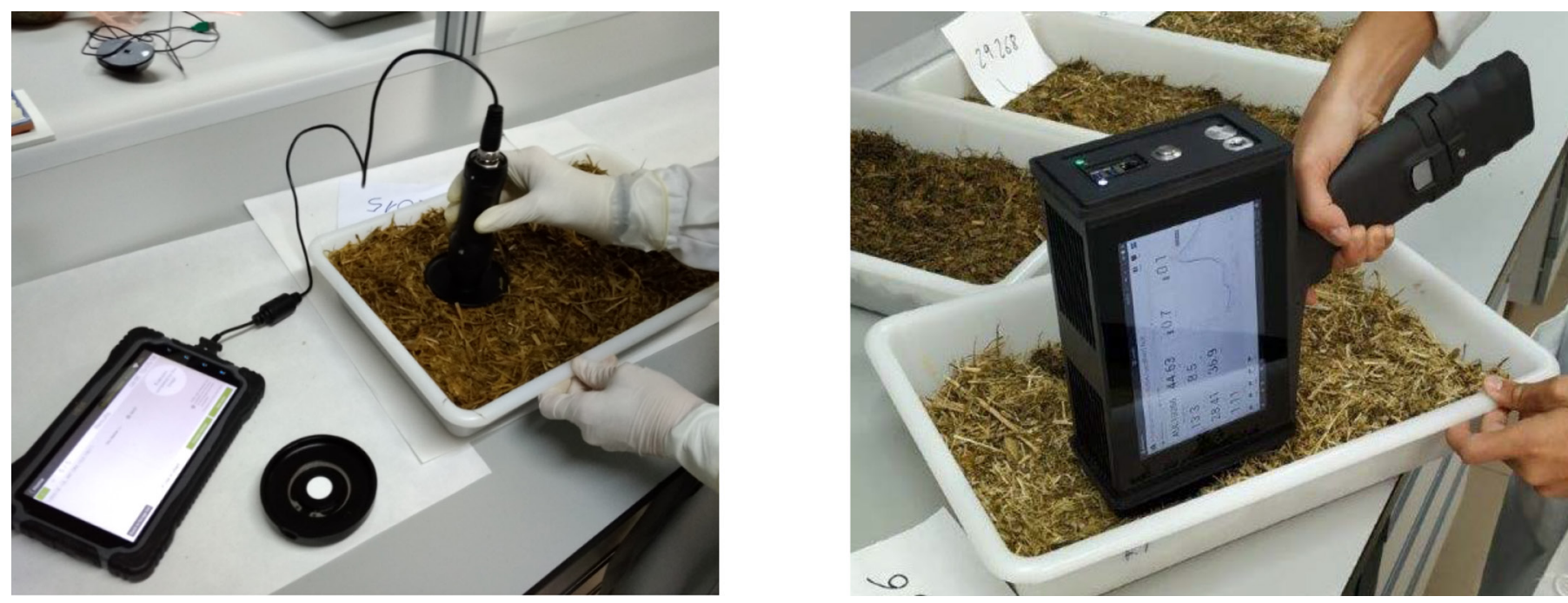

Figure 1. Near-infrared reflectance spectroscopy collection. Instruments: NIR4Farm (left; Aunir) and Aurora NIR (right; GraiNit S.R.L.).

tral range of 400 to $2,498 \mathrm{~nm}$ with a spectral wavelength interval of $2 \mathrm{~nm}$. This instrument was located at SERIDA's Nutrition Laboratory under controlled environmental conditions (temperature $24^{\circ} \mathrm{C} \pm 1^{\circ} \mathrm{C}$, relative humidity $50 \% \pm$ 10\%). Three spectra per sample were collected using a rectangular sample cup (Nature Product Sample Cup IH-0331, FOSS). In this case, 32 scans per spectrum were set. Spectra were recorded using ISIscan version 3 software (Infrasoft International LLC). This was used as the satellite instrument.

2. A portable handheld instrument, Aurora NIR (AU; GraiNit S.R.L.), working in the spectral range of 950 to $1,650 \mathrm{~nm}$ with a spectral resolution of $2 \mathrm{~nm}$ and equipped with a 256-pixel InGaAs photodiode array detector. This instrument is also equipped with a 7 -inch $(17.8 \mathrm{~cm})$ integrated PC. Spectra were collected in dynamic mode (i.e., keeping the analysis window in direct contact with the sample surface and moving the sensor over it along the acquisition of each spectrum). A total of 4 spectra per sample were collected without prior homogenization between measurements. This was used as the master 1 instrument.

3. A portable miniaturized instrument, NIR4Farm (N4F; Aunir), that uses linear variable filter technology and covers a range of wavelengths ranging from 920 to $1,658 \mathrm{~nm}$ with a spectral resolution of $2 \mathrm{~nm}$. The spectral data were collected using a small, rugged tablet connected to the device, using the NIR4 application software. Spectra were also collected in dynamic mode; however, 5 spectra were taken for each sample. In this case, a specifically designed accessory docked to the sensor was used to facilitate the analysis of such heterogeneous samples as TMR (Figure 1). This was used as the master 2 instrument.

Initially the 27 samples arrived at the University of Cordoba laboratory, where they were analyzed in their commercial or original presentation (i.e., without previous drying or milling) in the 2 portable spectrophotometers (AU and N4F). Subsequently, the 27 standardization samples were vacuum packed, refrigerated, and duly stored and then moved to the SERIDA's laboratory, where they were analyzed in the FNS spectrometer.

All measurements were made in reflectance mode $(\log 1 / \mathrm{R})$.

\section{Cloning}

Cloning procedure, data pre-processing, and chemometric treatments were performed using the WinISI II software package version 1.50 (Infrasoft International LLC; ISI, 2000).

Cloning or standardization are terms defined by Shenk and Westerhaus (1989) that refer to the mathematical process of adjusting the spectra recorded in one NIRS instrument (master) to make them appear and behave as if they were collected on the target instrument (satellite). The cloning or standardization is based on 2 main steps, namely estimation of the differences by measuring standardization samples on both instruments, and correction of those differences. In this 
research, instead of transferring the prediction models generated in the master instrument, the pre-existing libraries in the FNS equipment were standardized to the portable instruments to develop new prediction models based on them.

Because the FNS and the 2 portable instruments (AU and $\mathrm{N} 4 \mathrm{~F}$ ) used as masters have the same resolution, but differ in wavelength range, that parameter was adjusted for each couple of cloning devices (AU-FNS and N4F-FNS). The range of the FNS 6500 (400-2,500 $\mathrm{nm})$ was adapted, therefore, to the range of the Aurora NIR (950-1,650 nm), as well as to the range of the NIR4Farm (920-1,658 nm).

Next, instrumental standardization was carried out by applying the algorithm patented by Shenk and Westerhaus (1989), which performs the correction of the full spectrum in 2 stages; first, it performs a wavelength correction followed by a spectral intensity correction or correction of the photometric response of the satellite instrument. Both settings are stored in a standardization file, which is later used to transfer spectra between different instruments. Two cloning techniques, multisample and a single sample, were tested (Shenk and Westerhaus, 1989; Fearn, 2001; Pérez-Marín et al., 2006).

The number of standardization samples used for cloning is a key step (Fearn, 2001; Pérez-Marín et al., 2006), so it was decided to evaluate 2 strategies for the cloning set: (A) standardization matrices built with 9 samples and (B) standardization matrices built with 18 samples. In both cases, the remaining samples were used as the validation set for the evaluation of the cloning procedure. A total of 3 standardization matrices were developed for each option (A and B) and each couple of cloning devices using the cloning algorithm patented by Shenk and Westerhaus (1989), explained in detail by Pérez-Marín et al. (2006). The 3 cloning strategies evaluated for each option were (1a) 18 samples comprising the cloning set (STD18); (2a) the average spectrum of the 18 samples comprising the cloning set (STD18m); (3a) the sample closest to the center of the 18 cloning samples (STD18ce); (1b) 9 samples comprising the cloning set (STD9); (2b) the average spectrum of the 9 samples comprising the cloning set (STD9m); and (3b) the sample closest to the center of the 9 cloning samples (STD9ce).

The best strategy was evaluated first, using the RMS statistic (c) for the corresponding validation sets. The RMS (c), which was calculated using the CONTRAST algorithm included in the WINISI software, corresponds to the mean value of the square root of the differences, bias corrected, between spectra of the same sample obtained on the 2 instruments (master and satellite). It calculates using the expression
$\operatorname{RMS}(\mathrm{c})=$

$\sqrt{\frac{\sum_{\mathrm{i}=1}^{\mathrm{i}=\mathrm{n}}\left(\mathrm{y}_{\mathrm{i} \text { master }}-\mathrm{y}_{\mathrm{i} \text { satellite }}\right)-\frac{\left[\sum_{\mathrm{i}=1}^{\mathrm{i}=\mathrm{n}}\left(\mathrm{y}_{\mathrm{i} \text { master }}-\mathrm{y}_{\mathrm{i} \text { satellite }}\right)\right]^{2}}{\mathrm{n}-1}}{\mathrm{n}-1}}$

where $y_{i \text { master }}$ and $y_{i}$ satellite are the $\log (1 / R)$ values of 2 spectra of the same sample collected in the master and satellite equipment for a given i wavelength (Rosales, 1993; Shenk and Westerhaus, 1996).

To select the most appropriate standardization matrix, a 2-tailed Student's $t$-test was performed for 2 samples assuming equal variances, using the 2 sets of RMSc values for individual pairs of spectra in each validation set. Once the best standardization strategy was selected for each of the 2 cloning processes under study (FSN-AU and FSN-N4F), the spectral library of 394 samples was transferred to each portable spectrophotometer.

\section{Compositional Analysis of TMR}

The DM content was determined by drying the samples in a dry-forced oven $\left(60^{\circ} \mathrm{C}, 24 \mathrm{~h}\right)$ then milling through a $0.75-\mathrm{mm}$ sieve. The following chemical analyses were performed in the Animal Nutrition Laboratory of SERIDA, an accredited laboratory (ISO/IEC 17025; ISO, 2017): DM content of the TMR was established by heating to $103^{\circ} \mathrm{C}$ for $3 \mathrm{~h}$; ash by incineration to $550^{\circ} \mathrm{C}$ for $3 \mathrm{~h}$; $\mathrm{CP}(\mathrm{CP}=\mathrm{N} \times 6.25)$ by Kjeldahl analysis; ether extract by Soxhlet technique, including sample acid digestion before the extraction and CF by the Fibertec method (EC 152/2009; EC, 2009); ADF and NDF by Van Soest et al. (1991) and ISO 16472:2006 (ISO, 2006) for NDF and ISO 13906:2008 (ISO, 2008) for ADF; and starch content by enzymatic procedure after gelatinization and hydrolysis to glucose (Salomonsson et al., 1984) using the YSI 2700 Select Biochemistry Analyzer with some modifications (Soldado et al., 2003). Enzymatic digestibility of OM was determined following Riveros and Argamentería (1987).

Full reference data were not available for all samples, so the final number of samples used for each parameter was as follows: $\mathrm{DM}=394$, ash $=394, \mathrm{CP}=393, \mathrm{NDF}$ $=249, \mathrm{ADF}=357$, ether extract $=393$, crude fiber $=276$, and starch $=392$. All chemical analyses were expressed on a fresh basis.

\section{Calibration Development and Transfer Evaluation}

Before developing NIRS calibrations, the structure and spectral variability of the population were studied, determining the potential presence of spectral outli- 
ers. For this, the CENTER algorithm included in the WinISI II software (version 1.5) was applied to the spectral database of 394 samples in each instrument. After performing a principal component analysis and determining the center of the spectral population, this algorithm calculates the Mahalanobis distance of each sample to the center of the population. Those samples that presented a Mahalanobis distance $>3$ were considered spectral outliers, according to the criteria established by Shenk and Westerhaus (1996) for agroindustrial products.

Once outliers were identified and removed, calibrations with the original and with the transferred libraries were developed using modified partial least squares regression method combined with cross validation to determine the optimal number of terms and to detect the so-called chemical outliers in each instrument. In all cases, 4 cross-validation groups were established. Chemical outliers were detected using Student's t-test, where samples with a $t$-value over 2.5 were considered outliers (Mark and Workman, 1991). Spectra were pretreated using standard normal variate and de-trend for scatter correction (Barnes et al., 1989) combined with derivatives, testing 1.10.5.1 and 2.5.5.1, where the first digit is the number of the derivative, the second is the gap over which the derivative is calculated, the third is the number of data points in a running average or smoothing, and the fourth is the second smoothing (ISI, 2000).

For each master instrument (AU or N4F), the spectral region used corresponds to the range established for the cloning development, that is, from 1,100 to $1,650 \mathrm{~nm}$ (every $2 \mathrm{~nm}$ ) on the AU and from 1,100 to $1,658 \mathrm{~nm}$ (every $2 \mathrm{~nm}$ ) on the N4F. In the FNS instrument, the calibrations were carried out in its NIR region $(1,100-2,498 \mathrm{~nm}$, every $2 \mathrm{~nm})$.

The following statistics were used to evaluate and select the best calibration model for each of the study parameters: standard error of calibration, standard error of cross validation (SECV), and determination coefficient of cross validation. The other statistic used was residual predictive deviation (RPD; Williams and Sobering, 1996), calculated as the ratio between the standard deviation of the reference data for the training set and the SECV.

Once the best calibration models for each instrument and parameter were selected, to determine the loss of predictive capacity of the cloning carried out, Fisher's $F$-test was performed using Microsoft Excel 2019 version, to find significant differences between SECV values of each parameter and master-satellite pair (Massart et al., 1988; Næs et al., 2002). The $F$-statistic value was calculated as

$$
F=\frac{\mathrm{SECV}_{2}^{2}}{\mathrm{SECV}_{1}^{2}},
$$

with $\mathrm{SECV}_{1}<\mathrm{SECV}_{2}$. The $F$-value is compared with the critical $F$-value $\left[F_{\text {critical }}(1-\alpha, \mathrm{n} 1-1, \mathrm{n} 2-1)\right]$ obtained from the table of the $F$ distribution, where $\alpha$ is the significance level of the test, $\mathrm{n} 1$ is the number of times that the measurement is repeated with method 1 , and $\mathrm{n} 2$ is the number of times the measurement is repeated with method 2 . If $F>F_{\text {critical }}$, the differences between the compared SECV are considered significant.

Finally, the spectral data transfers were evaluated by comparing the predictions of the samples not involved in the development of the cloning matrix $(n=18)$ by each pair of master and satellite instruments. For this purpose, the standard error of the differences (SED), determination coefficient of the differences $\left(\mathbf{R}_{\mathbf{d}}{ }_{\mathbf{d}}\right)$, and SECV of the satellite instrument $\left(\mathbf{S E C V} \mathbf{V}_{\text {sat }}\right)$ statistics were used.

The most important statistic for the calibration performance comparison between the master and satellite instruments is the SED (Shenk et al., 2001). This statistic evaluates the total error, comprised by the unexplained error and the bias. To avoid the existence of systematic differences between instruments, the SED must be considered in the evaluation, which is calculated as

$$
\mathrm{SED}=\sqrt{\frac{\sum_{i=1}^{N}\left(\hat{y}_{i \text { master }}-\hat{y}_{\text {i satellite }}\right)^{2}}{N}},
$$

where $\hat{y}_{i \text { master }}$ and $\hat{y}_{i \text { satellite }}$ are the predicted values for each $i$ sample in the master and satellite instruments, respectively.

\section{RESULTS AND DISCUSSION}

\section{Standardization Process}

Before transferring the library, the different standardization matrices developed for each master-satellite cloning pair were evaluated. The results are shown in Tables 1 and 2, which lists RMS(c) values for each matrix used. Table 3 shows the mean, standard deviation, coefficient of variation, and range of the TMR library to be transferred. A key factor in the cloning process is the number of samples used both when selecting a procedure for standardizing NIRS instruments (Fearn, 2001; Pérez-Marín et al., 2006; Zamora-Rojas et al., 2012). Given the heterogeneity of the TMR samples and the important optical differences existing between 
Table 1. Spectral concordance between Aurora NIR (AU, GraiNit S.R.L.; master 1) and Foss NIRSystems 6500 (FNS; satellite) instruments before and after standardization

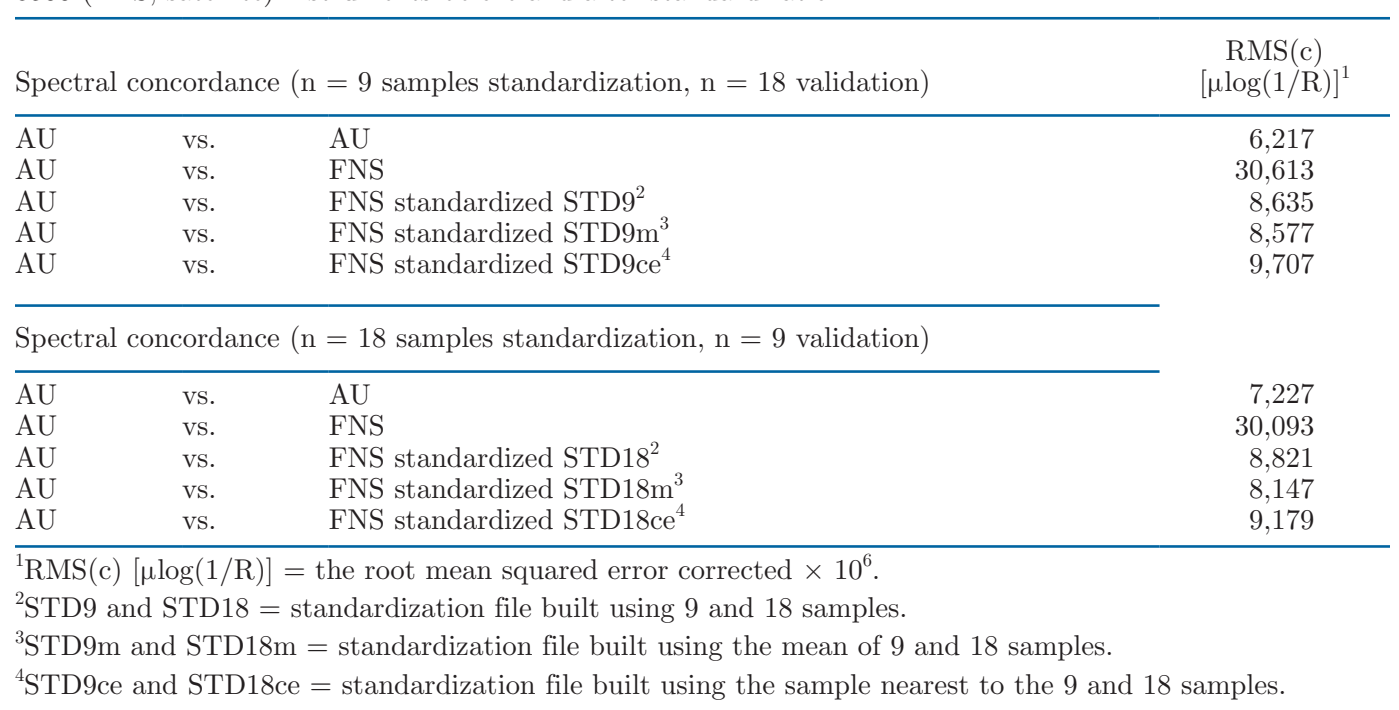

the FNS and the 2 portable instruments, it is expected that the cloning process needs several samples instead of only one to correct both axes corresponding to the absorbance differences and the alignment of the wavelengths. However, because using many samples is a costly process, it was evaluated in 2 different multisample sets $(\mathrm{n}=9$ and $\mathrm{n}=18)$ and 4 single sets (Pérez-Marín et al., 2006; Zamora-Rojas et al., 2012).

As a first approximation, the spectral differences between the master and satellite equipment were graphically observed before and after the different standardization strategies tested were carried out, as shown in Figures 2 and 3 . It can be appreciated that all the stan- dardization matrices achieved a near perfect overlap, at least visually, between the monochromator instrument (FNS) and the portable ones (AU and N4F).

Next, the magnitude of the spectral adjustment achieved was quantified using the RMS(c) statistic. The results are shown in Tables 1 and 2, which lists RMS(c) values for each matrix used. Significant differences were observed between the FNS and AU instruments [approximately 30,000 $\mu \log (1 / \mathrm{R})$ ] and between FNS and $\mathrm{N} 4 \mathrm{~F}$ [approximately $80,000 \mu \log (1 / \mathrm{R})$ ] before any standardization was performed. After the application of the different cloning matrices, these differences were significantly reduced, with some exceptions.

Table 2. Spectral concordance between NIR4Farm (N4F, Aunir; master 2) and FossNIRSystems 6500 (FNS; satellite) instruments before and after standardization

\begin{tabular}{|c|c|c|c|}
\hline \multicolumn{3}{|c|}{ Spectral concordance $(\mathrm{n}=9$ samples standardization, $\mathrm{n}=18$ validation $)$} & \multirow{2}{*}{$\begin{array}{c}\begin{array}{c}\mathrm{RMS}(\mathrm{c}) \\
{[\mu \log (1 / \mathrm{R})]^{1}}\end{array} \\
2,485\end{array}$} \\
\hline $\mathrm{N} 4 \mathrm{~F}$ & & $\mathrm{~N} 4 \mathrm{~F}$ & \\
\hline $\mathrm{N} 4 \mathrm{~F}$ & vs. & FNS & 79,249 \\
\hline $\mathrm{N} 4 \mathrm{~F}$ & vs. & FNS standardized STD9 ${ }^{2}$ & 14,586 \\
\hline $\mathrm{N} 4 \mathrm{~F}$ & vs. & FNS standardized STD9m ${ }^{3}$ & 24,594 \\
\hline $\mathrm{N} 4 \mathrm{~F}$ & vs. & FNS standardized STD9ce ${ }^{4}$ & 29,403 \\
\hline \multicolumn{3}{|c|}{ Spectral concordance $(\mathrm{n}=18$ samples standardization, $\mathrm{n}=9$ validation $)$} & \\
\hline $\mathrm{N} 4 \mathrm{~F}$ & vs. & $\mathrm{N} 4 \mathrm{~F}$ & 2,403 \\
\hline $\mathrm{N} 4 \mathrm{~F}$ & vs. & FNS & 84,297 \\
\hline $\mathrm{N} 4 \mathrm{~F}$ & vs. & FNS standardized STD $18^{2}$ & 11,200 \\
\hline $\mathrm{N} 4 \mathrm{~F}$ & vs. & FNS standardized STD $18 \mathrm{~m}^{3}$ & 25,004 \\
\hline $\mathrm{N} 4 \mathrm{~F}$ & vs. & FNS standardized STD18ce ${ }^{4}$ & 32,172 \\
\hline
\end{tabular}

${ }^{1} \operatorname{RMS}(\mathrm{c})[\mu \log (1 / \mathrm{R})]=$ the root mean squared error corrected $\times 10^{6}$.

${ }^{2}$ STD 9 and STD18 = standardization ile built using 9 and 18 samples.

${ }^{3}$ STD9m and STD18m = standardization file built using the mean of 9 and 18 samples.

${ }^{4}$ STD9ce and STD18ce $=$ standardization file built using the sample nearest to the 9 and 18 samples. 
Table 3. Statistics (mean, SD, CV, and range) for the entire TMR population

\begin{tabular}{lccrcc}
\hline Parameter $^{1}$ & N & Range & Mean & SD & CV (\%) \\
\hline DM (\% of fw) & 386 & $23.72-65.21$ & 46.45 & 7.26 & 15.64 \\
Ash (\% of fw) & 386 & $1.93-6.89$ & 4.06 & 0.83 & 20.52 \\
CP (\% of fw) & 385 & $2.76-11.57$ & 6.93 & 1.2 & 17.28 \\
ADF (\% of fw) & 350 & $5.45-18.91$ & 11.46 & 2.34 & 20.41 \\
NDF (\% of fw) & 242 & $9.38-32.51$ & 20.56 & 3.93 & 19.12 \\
Fat (\% of fw) & 385 & $0.31-3.43$ & 2.03 & 0.43 & 21.25 \\
CF (\% of fw) & 268 & $4.18-16.39$ & 9.92 & 2.14 & 21.58 \\
Starch (\% of fw) & 384 & $1.84-15.95$ & 8.18 & 2.29 & 28.03 \\
\hline
\end{tabular}

${ }^{1} \mathrm{CF}=$ crude fiber; $\mathrm{fw}=$ fresh weight.

In the case of the $\mathrm{AU}$ instrument, the RMS(c) values after cloning were in the range of 8,000 to $9,000 \mu \log$ $(1 / \mathrm{R})$; that is, cloning achieves a reduction of more than $1 / 3$ in the $\operatorname{RMS}(\mathrm{c})$ values. On the other hand, the cloning of the instruments $\mathrm{N} 4 \mathrm{~F}$ and FNS enabled us to achieve important reductions but only when the multisample strategy was applied. It is important to highlight that the multisample strategies (those that use several samples to build a standardization matrix) perform a spectral adjustment both at the level of the wavelength (abscissa) axis by means of a quadratic adjustment of the wavelengths, and of the absorption (ordinate) axis, by means of a linear adjustment of the slope at each wavelength. In contrast, those that use a single sample to build the standardization matrix only correct the differences at the level of the wavelength (abscissa) axis (Shenk and Westerhaus, 1989, 1991a).

In fact, as shown in the Figures 2 and 3, the spectral differences between the AU and the FNS instruments are of a different nature than those found between the FNS and the N4F instruments. It seems logical from the observation of these figures that more samples are required for the adjustment between the FNS and the $\mathrm{N} 4 \mathrm{~F}$ than in the case of the AU.

To make a conclusion on the suitability of using 9 or 18 samples to perform the transfer, and because there is no previous paper that dictates recommendations on the RMS(c) statistic value for cloning TMR samples, it was decided to compare, through a Student $t$-test, the values between the best standardization matrix (STD18) and the one developed from a smaller number of samples (STD9). No statistically significant differences could be observed between the RMS(c) values for $\mathrm{n}=18$ and $\mathrm{n}=9$ samples for both portable devices (AU and FN4). Because the existing differences in the RMS(c) values in the different cloning strategies studied, when using multisample approaches, do not differ from a statistical point of view, it was decided, for practical reasons, to select the STD9 matrices for both cloning procedures.
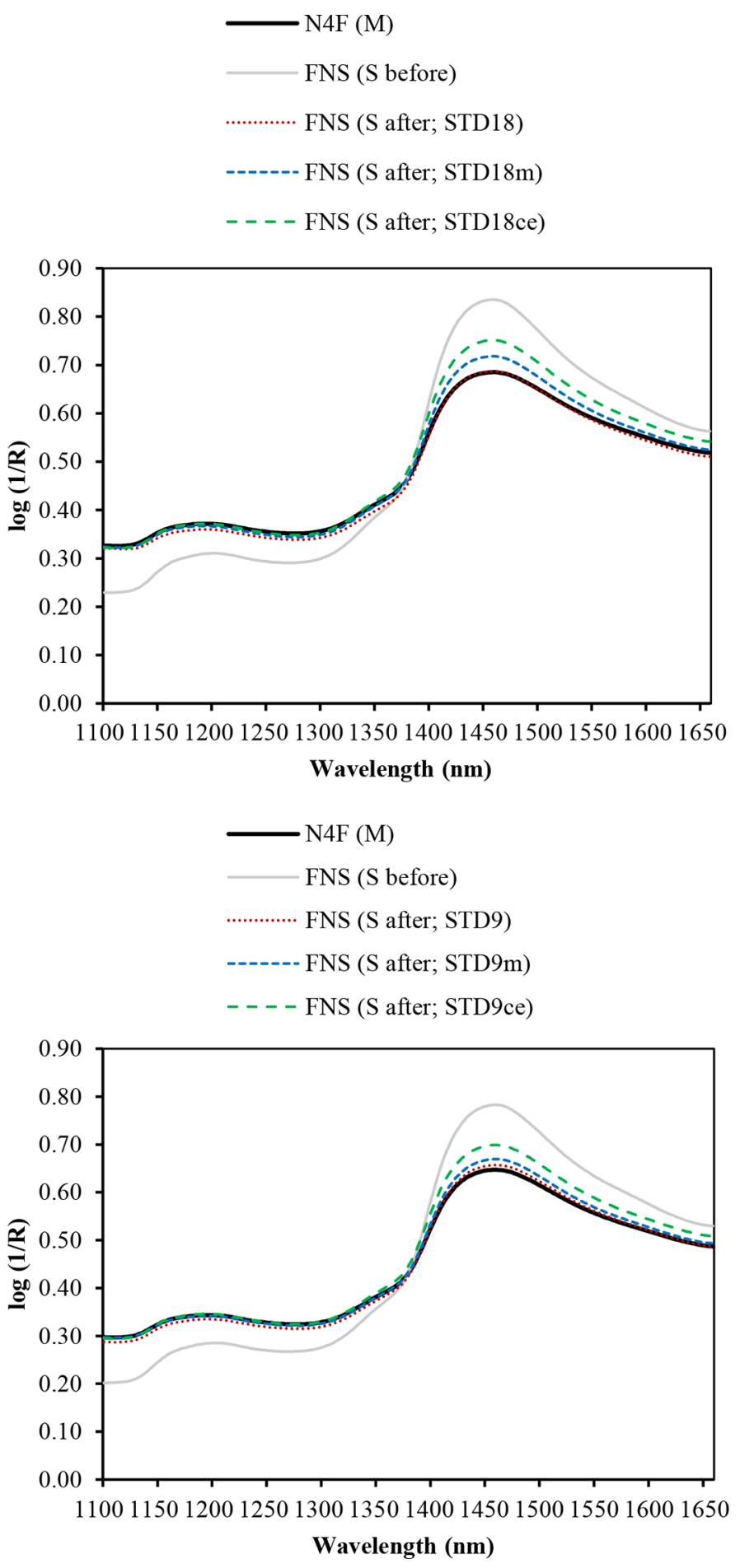

Figure 2. Mean spectrum of the validation sets analyzed in the NIR4Farm (N4F, Aunir; master, M) and the Foss NIRSystems 6500 (FNS; satellite, S) instruments, before and after the application of different standardization matrices. STD9 and STD18 = standardization file built using 9 and 18 samples. STD9m and STD18m = standardization file built using the mean of 9 and 18 samples. STD9ce and STD18ce $=$ standardization file built using the sample nearest to the 9 and 18 samples. $\mathrm{R}=$ reflectance. 

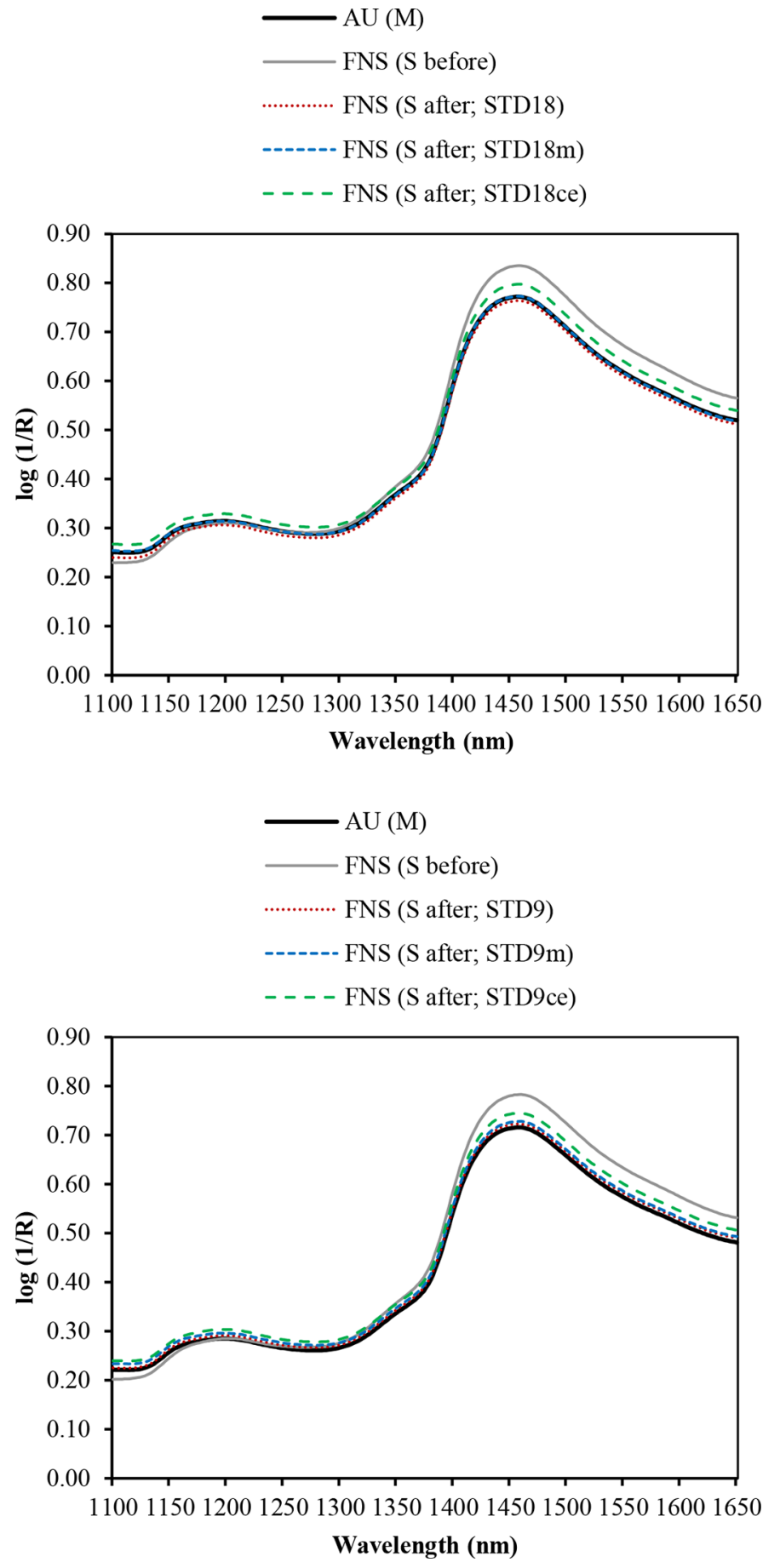

Figure 3. Mean spectrum of the validation sets analyzed in the Aurora NIR (AU; master, M) and the Foss NIRSystems (FNS; satellite, S) instruments, before and after the application of different standardization matrices. STD9 and STD18 = standardization file built using 9 and 18 samples. STD9m and STD18m = standardization file built using the mean of 9 and 18 samples. STD9ce and STD18ce $=$ standardization file built using the sample nearest to the 9 and 18 samples. $\mathrm{R}=$ reflectance.

\section{Calibration Development and Transfer Evaluation}

Once the best cloning matrix was selected for each of the 2 cloning processes under study (AU-FNS and N4F-FNS), the spectral library of 394 samples was transferred using the STD9 matrices. After each standardization, the resulted spectral database was processed with the CENTER algorithm. As indicated in Materials and Methods, the CENTER algorithm (Shenk and Westerhaus, 1991b) ranks spectral data based on their standardized $\mathrm{H}$ distance from the average spectrum. Eight samples were found with $\mathrm{H}>$ 3. After the detailed study of the samples identified as spectral outliers, it was found that these samples had extreme or poorly represented chemical values [i.e., high or low values for DM $(26.35 \%, 27.58 \%, 32.69 \%$, $64.96 \%, 67.04 \%, 68.08 \%, 76.25 \%)$, ADF (>30.72\%), or both], so it was decided to remove these samples from the spectral library.

To know the potential value of portable instruments for their use at the livestock farm level, the equations developed with the transferred database to each of the portable devices were compared with those obtained using the FNS spectral data.

The statistics of the best calibration models obtained for the prediction of bromatological parameters in TMR in each spectrophotometer are shown in Tables 4,5 , and 6 . It can be appreciated that the results, in terms of $\mathrm{R}^{2}$, SECV, and RPD, are similar for the 3 instruments evaluated. Shenk and Westerhaus (1996) reported that the goodness of fit of the calibrations for which $R^{2} \geq 0.9$ and $R^{2}=0.70$ to 0.89 may be regarded as excellent and good, respectively. The calibrations were inside these ranges for all the analytical parameters studied and for the 3 instruments.

The equation with the highest $\mathrm{R}^{2}$ was the one developed for DM. It is well known that DM is the most critical parameter to analyze in TMR because they contain important amounts of wet forages (fresh or silages), and wet forages differ themselves greatly in DM values. Therefore, the DM content of a TMR can oscillate even on different samples collected on the same day from the same front of a banker silo (Barbi et al., 2010). Furthermore, dairy rations are formulated on a DM basis and the amount of the feed fed to cows is on an as-is basis. Thus, distributing the diet according to weight is only accurate if its moisture content is accounted for (Severson, 2019). The equations obtained for DM (Tables 4, 5, and 6) have excellent precision and accuracy in the 3 instruments, explaining between 97 and $98 \%$ of the variance in DM of the TMR samples. The RPD values were 6.5 in both portable instruments, which far exceeds the value of 3 recommended by Williams and Sobering (1996). 
Table 4. Calibration statistics for the best near-infrared (NIR) based models for predicting bromatological composition in TMR using the Foss NIRSystems 6500 instrument $(\mathrm{n}=394 ; 1,100-2,498 \mathrm{~nm})$

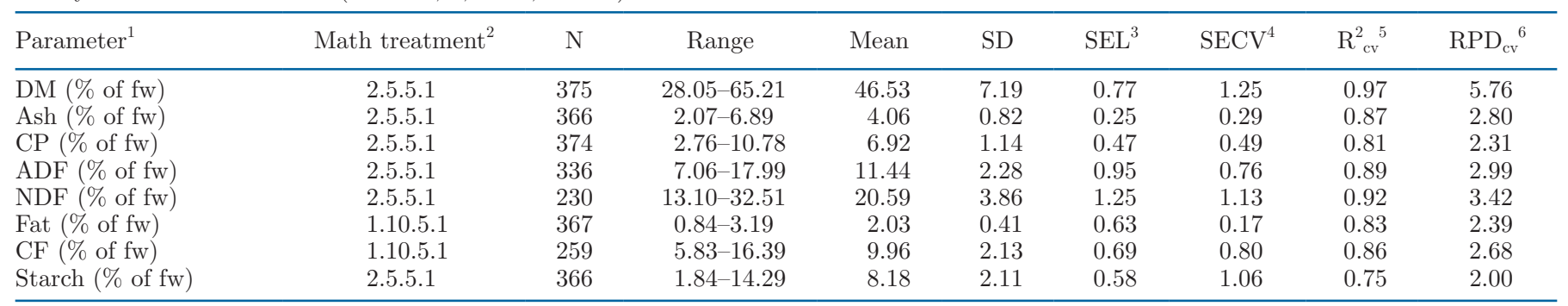

${ }^{1} \mathrm{CF}=$ crude fiber; $\mathrm{fw}=$ fresh weight.

${ }^{2}$ The first digit is the number of the derivative, the second is the gap over which the derivative is calculated, the third is the number of data points in a running average or smoothing, and the fourth is the second smoothing.

${ }^{3} \mathrm{SEL}=$ standard error of the laboratory.

${ }^{4} \mathrm{SECV}=$ standard error of cross validation.

${ }^{5} \mathrm{R}_{\mathrm{cv}}^{2}=$ determination coefficient of cross validation.

${ }^{6} \mathrm{RPD}_{\mathrm{cv}}=$ residual predictive deviation of cross validation.

Table 5. Calibration statistics for the best near-infrared (NIR) based models for predicting bromatological composition in TMR using the Aurora NIR (GraiNit S.R.L.) instrument after standardization with the matrix STD9 (9 samples comprising the cloning set)

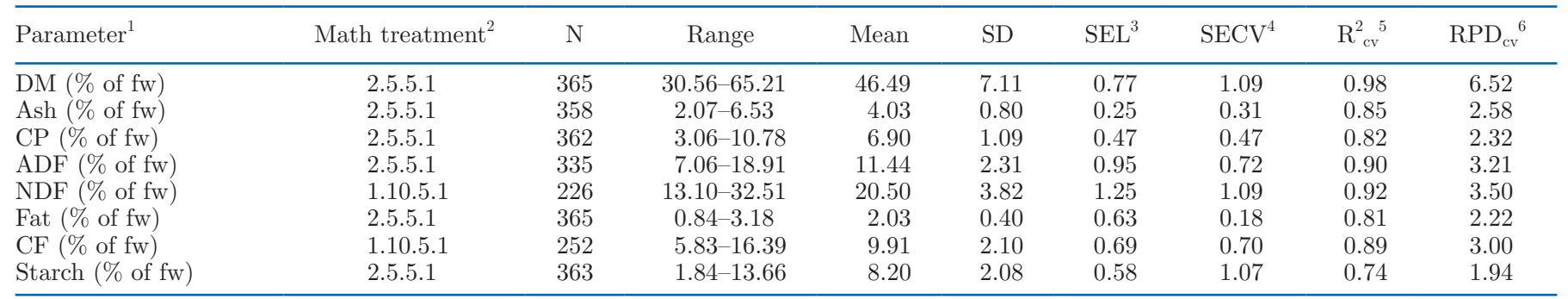

${ }^{1} \mathrm{CF}=$ crude fiber; fw $=$ fresh weight.

${ }^{2}$ The first digit is the number of the derivative, the second is the gap over which the derivative is calculated, the third is the number of data points in a running average or smoothing, and the fourth is the second smoothing.

${ }^{3} \mathrm{SEL}=$ standard error of the laboratory.

${ }^{4} \mathrm{SECV}=$ standard error of cross validation.

${ }^{5} \mathrm{R}_{\mathrm{cv}}^{2}=$ determination coefficient of cross validation.

${ }^{6} \mathrm{RPD}_{\mathrm{cv}}=$ residual predictive deviation of cross validation.

Table 6. Calibration statistics for the best near-infrared (NIR) based models for predicting bromatological composition in TMR using the NIR4Farm (Aunir) instrument after standardization with the matrix STD9 (9 samples comprising the cloning set)

\begin{tabular}{|c|c|c|c|c|c|c|c|c|c|}
\hline Parameter $^{1}$ & Math treatment ${ }^{2}$ & $\mathrm{~N}$ & Range & Mean & $\mathrm{SD}$ & $\mathrm{SEL}^{3}$ & $\mathrm{SECV}^{4}$ & $\mathrm{R}_{\mathrm{cv}}^{25}$ & $\mathrm{RPD}_{\mathrm{cv}}{ }^{6}$ \\
\hline Ash (\% of fw) & 2.5 .5 .1 & 352 & $2.07-6.53$ & 4.04 & 0.79 & 0.25 & 0.29 & 0.86 & 2.72 \\
\hline $\mathrm{CP}(\%$ of $\mathrm{fw})$ & 2.5 .5 .1 & 366 & $2.76-10.78$ & 6.90 & 1.14 & 0.47 & 0.49 & 0.81 & 2.33 \\
\hline $\operatorname{NDF}(\%$ of $\mathrm{fw})$ & 1.10.5.1 & 231 & $13.10-32.51$ & 20.58 & 3.84 & 1.25 & 1.15 & 0.91 & 3.34 \\
\hline Fat $(\%$ of $\mathrm{fw})$ & 2.5 .5 .1 & 367 & $0.84-3.19$ & 2.04 & 0.40 & 0.63 & 0.18 & 0.80 & 2.22 \\
\hline $\mathrm{CF}(\%$ of $\mathrm{fw})$ & 1.10.5.1 & 257 & $5.83-16.39$ & 9.92 & 2.10 & 0.69 & 0.74 & 0.88 & 2.84 \\
\hline
\end{tabular}

${ }^{1} \mathrm{CF}=$ crude fiber; $\mathrm{fw}=$ fresh weight.

${ }^{2}$ The first digit is the number of the derivative, the second is the gap over which the derivative is calculated, the third is the number of data points in a running average or smoothing, and the fourth is the second smoothing.

${ }^{3} \mathrm{SEL}=$ standard error of the laboratory.

${ }^{4} \mathrm{SECV}=$ standard error of cross validation.

${ }^{5} \mathrm{R}_{\mathrm{cv}}^{2}=$ determination coefficient of cross validation.

${ }^{6} \mathrm{RPD}_{\mathrm{cv}}=$ residual predictive deviation of cross validation. 
Table 7. Comparison between the standard error of cross validation (SECV) values obtained with the best models for predicting TMR quality using the Foss NIRSystems 6500 (FNS) or the Aurora NIR (AU; GraiNit S.R.L.) after the cloning process; Fisher test $(P<0.05)$

\begin{tabular}{lcccc}
\hline Parameter $^{1}$ & SECV AU & SECV FNS & $F$ & $F_{\text {critical }^{2}}$ \\
\hline DM (\% of fw) & 1.09 & 1.25 & $1.31^{*}$ & 1.19 \\
Ash (\% of fw) & 0.31 & 0.29 & 1.14 & 1.19 \\
CP (\% of fw) & 0.47 & 0.49 & 1.09 & 1.19 \\
ADF (\% of fw) & 0.72 & 0.76 & 1.11 & 1.20 \\
NDF (\% of fw) & 1.09 & 1.13 & 1.07 & 1.24 \\
Fat (\% of fw) & 0.18 & 0.17 & 1.12 & 1.19 \\
CF (\% of fw) & 0.70 & 0.80 & $1.31^{*}$ & 1.23 \\
Starch (\% of fw) & 1.07 & 1.06 & 1.02 & 1.19 \\
\hline
\end{tabular}

${ }^{1} \mathrm{CF}=$ crude fiber; $\mathrm{fw}=$ fresh weight.

${ }^{2} F_{\text {critical }}=$ critical $F$-value.

*Significant difference $(P<0.05)$.

As noted in the Introduction section of this work, the NIRS studies related to TMR are rather limited in relation to those published in forages and feeds. The first 2 papers published about the performance of NIRS for TMR analysis were published by Soldado et al. (2009) and Ki et al. (2009). The first authors used a collection of 183 samples analyzed in a laboratory instrument to develop calibrations for the same analytical parameter studied in this research. Having taken into account that the calibration set used by Soldado et al. (2009) and our own calibration set are similar in terms of mean, range, and SD of the reference data, the highest $\mathrm{R}^{2}$ and lowest SECV values obtained by us may be explained by the higher number of samples used in the present paper $(\mathrm{n}=394)$.

Ki et al. (2009) used a collection of 253 TMR samples collected from producers and dairy farms in Korea. The $\mathrm{R}^{2}$ for moisture prediction (0.70) was lower than those shown in Tables 4, 5, and 6 of the present work. However, for the rest of parameters the results were more similar at $0.97,0.89,0.90,0.93,0.90$, and 0.80 for $\mathrm{CP}$, $\mathrm{CF}$, ash, ADF, NDF, and fat, respectively. Nevertheless, it is important to stress that the equations were obtained by using dried and fine milled samples and the reference data were expressed on a DM basis, whereas in our case the samples were analyzed fresh and the data were expressed as is. Therefore, it is not possible to compare the SECV values of both papers.

There is another important difference between the 2 above-mentioned papers and the present one. Soldado et al. (2009) and Ki et al. (2009) developed calibrations using research-grade instruments covering the full VIS + NIR range. In this paper, a more limited region of the electromagnetic spectrum has been used.

To get a better evaluation of the quality of the transference done from a research-grade spectrophotometer to the 2 studied portable instruments, the SECV values obtained for each equation and instrument were compared using a $F$-test (Tables 7 and 8).

For the AU instrument, there are 2 equations (DM and $\mathrm{CF}$ ) in which there are significant differences with the monochromator results, but curiously the AU instrument has lower SECV values than the FNS instrument (Table 7). In the case of the $\mathrm{N} 4 \mathrm{~F}$, this fact also happens for the DM equation (Table 8).

Although all of the equations have been developed on an as-is basis, it is crucial to explain that a previous publication (Pérez-Marín et al., 2021) demonstrated that the accuracy of the equations obtained when data are expressed on a DM basis is lower than the one obtained when data are expressed on an as-is basis. However, to help nutritionists see results expressed on a DM basis, the statistics obtained by Pérez-Marín et al. (2021) are reported in Table 9.

Finally, the predicted data for the $\mathrm{n}=18$ samples that did not contribute to the cloning set were predicted by each instrument. Subsequently, the SED values were calculated and then compared with the $\mathrm{SECV}_{\text {sat }}$ (Tables 10 and 11).

As can be seen for the AU instrument, in terms of $\mathrm{R}_{\mathrm{d}}^{2}$, all the parameters showed values over 0.88 . Furthermore, for the parameters DM, NDF, and CF, the values of the SED $(1.02,0.82,0.47)$ were lower than those of the $\operatorname{SECV}_{\text {sat }}(1.25,1.13,0.80)$, indicating excellent performance. Additionally, for the ADF and fat parameters, lower differences between these statistics were observed $(0.81-0.76 ; 0.22-0.17$, respectively). For the rest of the parameters under study (ash, CP, and starch), the differences were high, especially for the starch, which was the parameter whose calibration had the lowest predictive capacity $(\mathrm{RPD}=2.00$ in FNS instrument).

A reason for that could be that the samples of the $\mathrm{n}=18$ set came from different geographical locations

Table 8. Comparison between the standard error of cross validation (SECV) values obtained with the best models for predicting TMR quality using the Foss NIRSystems 6500 (FNS; Foss NIRsystems Inc.) or the NIR4Farm (N4F; Aunir) after the cloning process; Fisher test $(P<0.05)$

\begin{tabular}{lcccc}
\hline Parameter $^{1}$ & SECV N4F & SECV FNS & $F$ & $F_{\text {critical }^{2}}$ \\
\hline DM (\% of fw) & 1.09 & 1.25 & $1.32^{*}$ & 1.19 \\
Ash (\% of fw) & 0.29 & 0.29 & 1.00 & 1.19 \\
CP (\% of fw) & 0.49 & 0.49 & 1.00 & 1.19 \\
ADF (\% of fw) & 0.72 & 0.76 & 1.11 & 1.20 \\
NDF (\% of fw) & 1.15 & 1.13 & 1.04 & 1.24 \\
Fat (\% of fw) & 0.18 & 0.17 & 1.12 & 1.19 \\
CF (\% of fw) & 0.74 & 0.80 & 1.17 & 1.23 \\
Starch (\% of fw) & 1.1 & 1.06 & 1.08 & 1.19 \\
\hline
\end{tabular}

${ }^{1} \mathrm{CF}=$ crude fiber; $\mathrm{fw}=$ fresh weight.

${ }^{2} F_{\text {critical }}=$ the critical $F$-value.

*Significant difference $(P<0.05)$. 
Table 9. Calibration statistics for the best near-infrared (NIR) based models for predicting bromatological composition expressed as DM in TMR using the Foss NIRSystems 6500 instrument (FNS 6500), or the Aurora (GraiNit S.R.L.) and NIR4Farm (Aunir) instruments after the cloning process

\begin{tabular}{|c|c|c|c|c|}
\hline Parameter $^{1}$ & Instrument & $\mathrm{SEL}^{2}$ & $\mathrm{SECV}^{3}$ & $\mathrm{R}^{2}$ \\
\hline \multirow[t]{3}{*}{ Ash (\% of DM) } & FNS 6500 & 0.15 & 0.52 & 0.79 \\
\hline & Aurora & & 0.70 & 0.63 \\
\hline & N4Farm & & 0.70 & 0.63 \\
\hline \multirow[t]{3}{*}{$\mathrm{CP}(\%$ of $\mathrm{DM})$} & FNS 6500 & 0.33 & 0.83 & 0.66 \\
\hline & Aurora & & 1.62 & 0.56 \\
\hline & N4Farm & & 0.96 & 0.57 \\
\hline \multirow{3}{*}{$\mathrm{ADF}(\%$ of $\mathrm{DM})$} & FNS 6500 & 0.70 & 1.47 & 0.63 \\
\hline & Aurora & & 1.63 & 0.60 \\
\hline & N4Farm & & 1.66 & 0.58 \\
\hline \multirow{3}{*}{ NDF ( $\%$ of DM) } & FNS 6500 & 1.25 & 2.45 & 0.61 \\
\hline & Aurora & & 2.78 & 0.59 \\
\hline & N4Farm & & 2.86 & 0.57 \\
\hline \multirow[t]{3}{*}{ Fat (\% of DM) } & FNS 6500 & 0.51 & 0.37 & 0.75 \\
\hline & Aurora & & 0.38 & 0.77 \\
\hline & N4Farm & & 0.39 & 0.76 \\
\hline \multirow[t]{3}{*}{ CF (\% of DM) } & FNS 6500 & 0.62 & 1.62 & 0.61 \\
\hline & Aurora & & 1.81 & 0.59 \\
\hline & N4Farm & & 1.80 & 0.58 \\
\hline \multirow{3}{*}{ Starch (\% of DM) } & FNS 6500 & 0.38 & 1.83 & 0.70 \\
\hline & Aurora & & 2.18 & 0.60 \\
\hline & N4Farm & & 2.13 & 0.61 \\
\hline
\end{tabular}

${ }^{1} \mathrm{CF}=$ crude fiber.

${ }^{2} \mathrm{SEL}=$ standard error of the laboratory.

${ }^{3} \mathrm{SECV}=$ standard error of cross validation.

than those that compose the database, and therefore they are not well represented in the calibration set. Furthermore, as reported by Eilert and Gajewski (2005), after a database transference to a new instrument, new samples should be added to improve calibration performance. A new project is being undertaken to add samples from different locations to the databases of the 2 portable instruments. However, the main goal of the present paper has been reached, which was that the data produced for years, by using high-cost and research-grade at-line NIRS instruments, were moved successfully to portable on-farm instruments, avoiding the need to restart calibrations from the beginning.

On the other hand, for the N4F instrument, the $\mathrm{R}_{\mathrm{d}}^{2}$ values were higher than 0.89 for all of the parameters except for ash (0.79). Moreover, for the $\mathrm{CP}$ and $\mathrm{ADF}$ parameters, the SED values $(0.44,0.75)$ were also inferior to the $\operatorname{SECV}_{\text {sat }}$ ones $(0.49,0.76)$, which demonstrates an excellent adjustment. In addition, for $\mathrm{CP}$, fat, and $\mathrm{CF}$, the values of the errors were similar $(0.44-0.49$, $0.19-0.17$, and $0.84-0.80$, respectively). Finally, for the NDF and starch parameters the differences between the statistics studied were higher.

\section{CONCLUSIONS}

High precision and accuracy were obtained for all analytical parameters predicted in TMR and for the 2 on-farm instruments. The 2 portable instruments studied had almost the same predictive ability. The excellent results obtained to predict DM in TMR ensure greater matching between what a nutritionist formulates and what the cows consume. Moreover, we have shown the feasibility of transferring a large collection of existing TMR samples analyzed in an at-line and high-cost instrument to portable NIR instruments that can be used at the livestock farm level, making NIRS technology essential for consideration within precision feeding

Table 10. Statistics of Foss NIRSystems 6500 (FNS 6500) versus Aurora (GraiNit S.R.L.) predicted data for the $\mathrm{n}=18$ set

\begin{tabular}{|c|c|c|c|c|c|c|c|}
\hline Parameter $^{1}$ & Instrument & Means & $\mathrm{SD}$ & Slope & $\mathrm{R}_{\mathrm{d}}^{2}$ & $\mathrm{SED}^{3}$ & $\mathrm{SECV}_{\mathrm{sat}}{ }^{4}$ \\
\hline \multirow[t]{2}{*}{$\mathrm{DM}(\%$ of $\mathrm{fw})$} & FNS 6500 & 49.50 & 8.95 & 0.91 & 1.00 & 1.02 & 1.25 \\
\hline & Aurora & 49.32 & 9.88 & & & & \\
\hline \multirow{2}{*}{$\operatorname{Ash}(\%$ of fw) } & FNS 6500 & 3.52 & 0.76 & 1.03 & 0.88 & 0.70 & 0.29 \\
\hline & Aurora & 4.17 & 0.69 & & & & \\
\hline \multirow[t]{2}{*}{$\mathrm{CP}(\%$ of $\mathrm{fw})$} & FNS 6500 & 7.60 & 1.34 & 0.82 & 0.93 & 0.82 & 0.49 \\
\hline & Aurora & 8.29 & 1.57 & & & & \\
\hline \multirow[t]{2}{*}{$\operatorname{ADF}(\%$ of $\mathrm{fw})$} & FNS 6500 & 12.25 & 1.81 & 0.71 & 0.96 & 0.81 & 0.76 \\
\hline & Aurora & 12.28 & 2.49 & & & & \\
\hline \multirow[t]{2}{*}{$\mathrm{NDF}(\%$ of $\mathrm{fw})$} & FNS 6500 & 19.68 & 3.25 & 0.89 & 0.98 & 0.82 & 1.13 \\
\hline & Aurora & 19.16 & 3.60 & & & & \\
\hline \multirow[t]{2}{*}{ Fat (\% of fw) } & FNS 6500 & 1.87 & 0.59 & 0.94 & 0.97 & 0.22 & 0.17 \\
\hline & Aurora & 1.68 & 0.61 & & & & \\
\hline \multirow{2}{*}{$\mathrm{CF}(\%$ of $\mathrm{fw})$} & FNS 6500 & 10.55 & 1.49 & 0.88 & 0.95 & 0.47 & 0.80 \\
\hline & Aurora & 10.29 & 1.66 & & & & \\
\hline \multirow[t]{2}{*}{ Starch (\% of fw) } & FNS 6500 & 12.43 & 2.29 & 0.68 & 0.92 & 3.17 & 1.06 \\
\hline & Aurora & 9.48 & 3.21 & & & & \\
\hline
\end{tabular}

${ }^{1} \mathrm{CF}=$ crude fiber; $\mathrm{fw}=$ fresh weight.

${ }^{2} \mathrm{R}_{\mathrm{d}}^{2}=$ coefficient of determination of the differences.

${ }^{3} \mathrm{SED}=$ standard error of the differences.

${ }^{4} \mathrm{SECV}_{\text {sat }}=$ standard error of cross validation of the satellite instrument (FNS 6500). 
Table 11. Statistics of Foss NIRSystems 6500 (FNS 6500) versus N4Farm (Aunir) predicted data for the $\mathrm{n}$ $=18$ set

\begin{tabular}{|c|c|c|c|c|c|c|c|}
\hline Parameter $^{1}$ & Instrument & Means & $\mathrm{SD}$ & Slope & $\mathrm{R}_{\mathrm{d}}^{2}$ & $\mathrm{SED}^{3}$ & $\mathrm{SECV}_{\text {sat }}{ }^{4}$ \\
\hline \multirow[t]{2}{*}{$\mathrm{DM}(\%$ of $\mathrm{fw})$} & FNS 6500 & 49.5 & 8.95 & 0.96 & 0.99 & 2.02 & 1.25 \\
\hline & N4Farm & 47.63 & 9.3 & & & & \\
\hline \multirow[t]{2}{*}{ Ash (\% of fw) } & FNS 6500 & 3.52 & 0.76 & 1.23 & 0.79 & 0.41 & 0.29 \\
\hline & N4Farm & 3.31 & 0.55 & & & & \\
\hline \multirow[t]{2}{*}{$\mathrm{CP}(\%$ of $\mathrm{fw})$} & FNS 6500 & 7.6 & 1.34 & 0.99 & 0.89 & 0.44 & 0.49 \\
\hline & N4Farm & 7.5 & 1.28 & & & & \\
\hline \multirow{2}{*}{$\operatorname{ADF}(\%$ of $\mathrm{fw})$} & FNS 6500 & 12.25 & 1.81 & 0.86 & 0.97 & 0.75 & 0.76 \\
\hline & N4Farm & 12.86 & 2.06 & & & & \\
\hline \multirow{2}{*}{$\mathrm{NDF}$ (\% of fw) } & FNS 6500 & 19.68 & 3.25 & 0.82 & 0.98 & 2.01 & 1.13 \\
\hline & N4Farm & 17.84 & 3.93 & & & & \\
\hline \multirow[t]{2}{*}{ Fat (\% of fw) } & FNS 6500 & 1.87 & 0.59 & 0.99 & 0.96 & 0.19 & 0.17 \\
\hline & N4Farm & 1.73 & 0.58 & & & & \\
\hline \multirow{2}{*}{$\mathrm{CF}(\%$ of $\mathrm{fw})$} & FNS 6500 & 10.55 & 1.49 & 0.79 & 0.95 & 0.84 & 0.80 \\
\hline & N4Farm & 9.87 & 1.85 & & & & \\
\hline \multirow[t]{2}{*}{ Starch (\% of fw) } & FNS 6500 & 12.43 & 2.29 & 0.73 & 0.93 & 1.84 & 1.06 \\
\hline & N4Farm & 10.89 & 3.04 & & & & \\
\hline
\end{tabular}

${ }^{1} \mathrm{CF}=$ crude fiber; $\mathrm{fw}=$ fresh weight.

${ }^{2} \mathrm{R}_{\mathrm{d}}^{2}=$ coefficient of determination of the differences.

${ }^{3} \mathrm{SED}=$ standard error of the differences

${ }^{4} \mathrm{SECV}_{\text {sat }}=$ standard error of cross validation of the satellite instrument (FNS 6500).

strategies. The library file on each instrument should be expanded, especially with samples from different agro-climatic regions. This will facilitate a universal sample set of use on many dairy farms and research and extension laboratories around the world.

\section{ACKNOWLEDGMENTS}

This research was carried out as part of the research project RTA2015-00020-C02-02 'Use of NIRS sensors for decision making in dairy farms based on the individual complete diet quality for each animal,' funded by the Ministerio de Economía, Industria y Competitividad. The funding source was not involved in the preparation of this article. The authors have not stated any conflicts of interest.

\section{REFERENCES}

Barbi, A., A. Ghiraldi, M. Manzoli, and P. Berzaghi. 2010. Precision feeding: NIR on line for improving TMR consistency. The First North American Conference on Precision Dairy Management 2010. Accessed Mar. 17, 2021. http://precisiondairy.com/proceedings/ s11barbi.pdf.

Barnes, R. J., M. S. Dhanoa, and S. J. Lister. 1989. Standard normal variate transformation and de-trending of near infrared diffuse reflectance spectra. Appl. Spectrosc. 43:772-777. https://doi.org/10 $.1366 / 0003702894202201$.

Beć, K. B., J. Grabska, H. W. Siesler, and C. W. Huck. 2020. Handheld near-infrared spectrometers: Where are we heading? NIR News 31:28-35. https://doi.org/10.1177/0960336020916815.

Coelho, M., F. G. Hembry, F. E. Barton, and A. M. Saxton. 1988. A comparison of microbial, enzymatic, chemical and near-infrared reflectance spectroscopy methods in forage evaluation. Anim. Feed Sci. Technol. 20:219-231. https://doi.org/10.1016/0377 -8401(88)90045-4.
Crocombe, R. A. 2018. Portable spectroscopy. Appl. Spectrosc. 72:1701-1751. https://doi.org/10.1177/0003702818809719.

Decruyenaere, V., P. Lecomte, C. Demarquilly, J. Aufrere, P. Dardenne, D. Stilmant, and A. Buldgen. 2009. Evaluation of green forage intake and digestibility in ruminants using near infrared reflectance spectroscopy (NIRS): Developing a global calibration. Anim. Feed Sci. Technol. 148:138-156. https://doi.org/10.1016/j .anifeedsci.2008.03.007.

Eilert, A. J., and R. Gajewski. 2005. White paper: Moving up to next generation NIR technology without losing your existing calibration database. Accessed Mar. 25, 2021. http://www.jie-rui-instrument .tw/product/Unity\%20Scientific/NIR001_Unity.pdf.

EC (European Commission). 2009. Commission Regulation (EC) No 152/2009 of 27 January 2009 laying down the methods of sampling and analysis for the official control of feed. Off. J. Eur. Union L 54:1-130.

Evangelista, C., L. Basiricò, and U. Bernabucci. 2021. An overview on the use of near infrared spectroscopy (NIRS) on farms for the management of dairy cows. Agriculture 11:296. https://doi.org/10 .3390 /agriculture11040296.

Fearn, T. 2001. Standardisation and calibration transfer for near infrared instruments: A review. J. Near Infrared Spectrosc. 9:229-244 https://doi.org/10.1255/jnirs.309.

Fernández-Ahumada, E., A. Garrido-Varo, J. E. Guerrero, D. PérezMarín, and T. Fearn. 2008. Taking NIR calibrations of feed compounds from the laboratory to the process: Calibration transfer between pre-dispersive and post dispersive instruments. J. Agric. Food Chem. 56:10135-10141. https://doi.org/10.1021/jf801881n.

ISI. 2000. The complete software solution using a single screen for routine analysis, robust calibrations, and networking. Manual Foss NIRSystems/Tecator.

ISO. 2006. ISO 16472:2006. Animal feeding stuffs - Determination of amylase-treated neutral detergent fibre content (aNDF). International Organization for Standardization.

ISO. 2008. ISO 13906:2008: Animal feeding stuffs - Determination of acid detergent fibre (ADF) and acid detergent lignin (ADL) contents. International Organization for Standardization.

ISO. 2017. ISO/IEC 17025:2017. General Requirements for the Competence of Testing and Calibration Laboratories. International Organization for Standardization.

James, R. E., and B. Cox. 2008. Feeding management to reduce the environmental impact of dairy farms. Vol. 31 in Proc. 45th Florida Dairy Production Conference. University of Florida. 
Kertz, A. F. 1998. Variability in delivery of nutrients to lactating dairy cows. J. Dairy Sci. 81:3075-3084. https://doi.org/10.3168/ jds.S0022-0302(98)75872-2.

Ki, K.-S., S.-B. Kim, H.-J. Lee, S.-H. Yang, J.-S. Lee, Z.-L. Jin, H.-S. Kim, J.-M. Jeo, J.-Y. Koo, and J.-K. Cho. 2009. Prediction on the quality of total mixed ration for dairy cows by near infrared reflectance spectroscopy. Korean Soc. Grassl. Forage Sci. 29:253-262. https://doi.org/10.5333/KGFS.2009.29.3.253.

Mark, H., and J. Workman. 1991. Statistics in Spectroscopy. Academic Press Inc.

Massart, D. L., B. G. M. Vandeginste, S. M. Deming, Y. Michotte, and L. Kaufman. 1988. Chemometrics: A textbook. Data Handling in Science and Technology 2. Elsevier Science.

McCoy, G. C., H. S. Thurmon, H. H. Olson, and A. Reed. 1966. Complete feed rations for lactating dairy cows. J. Dairy Sci. 49:1058 1063. https://doi.org/10.3168/jds.S0022-0302(66)88017-7.

Mentink, R. L., P. C. Hoffman, and L. M. Bauman. 2006. Utility of near-infrared reflectance spectroscopy to predict nutrient composition and in vitro digestibility of total mixed rations. J. Dairy Sci. 89:2320-2326. https://doi.org/10.3168/jds.S0022-0302(06)72303 -7 .

Miller-Cushon, E. K., and T. J. DeVries. 2017. Feed sorting in dairy cattle: Causes, consequences, and management. J. Dairy Sci. 100:4172-4183. https://doi.org/10.3168/jds.2016-11983.

Næs, T., T. Isaksson, T. Fearn, and T. Davies. 2002. A User Friendly Guide to Multivariate Calibration and Classification. NIR Publications.

Norris, K. H., R. P. Barnes, J. E. Moore, and J. S. Shenk. 1976. Predicting forage quality by infrared reflectance spectroscopy. J. Anim. Sci. 43:889-897. https://doi.org/10.2527/jas1976.434889x.

Park, R. S., R. E. Agnew, F. J. Gordon, and R. W. J. Steen. 1998. The use of near infrared reflectance spectroscopy (NIRS) on undried samples of grass silage to predict chemical composition and digestibility parameters. Anim. Feed Sci. Technol. 72:155-167. https:// doi.org/10.1016/S0377-8401(97)00175-2.

Pérez-Marín, D., B. De la Roza, J. A. Entrenas, M. Garrido-Cuevas, and A. Garrido-Varo. 2021. "Comparison of the predictive ability of NIR calibration models developed to predict nutritional parameters in total mixed rations by using reference data expressed "as dry matter" or "as is basis." Proc. SPIE 11754. Sensing for Agriculture and Food Quality and Safety XIII, 1175404. https:// doi.org/10.1117/12.2588239.

Pérez-Marín, D., A. Garrido-Varo, and J. E. Guerrero-Ginel. 2006. Remote near infrared instrument cloning and transfer of calibrations to predict ingredient percentages in intact compound feedstuffs. J. Near Infrared Spectrosc. 14:81-91. https://doi.org/10.1255/jnirs .594 .

Riveros, E., and A. Argamentería. 1987. Métodos enzimáticos de predicción de la digestibilidad in vivo de la materia orgánica de forrajes. Av. Prod. Anim. 12:49-58.

Rosales, M. 1993. Uso de la información espectroscópica NIRS "per se" en la evaluación de la calidad de productos agrícolas. Trabajo Profesional Fin de Carrera. ETSIAM. Universidad de Córdoba.

Salomonsson, A. C., O. Theander, and E. Westerlund. 1984. Chemical characterization of some Swedish cereal whole meal and brand factors. Swed. J. Agric. Res. 14:111-117.

Saranwong, S., and S. Kawano. 2005. Commercial portable NIR instruments in Japan. NIR News 16:27-30. https://doi.org/10.1255/ nirn.859.

Schingoethe, D. J. 2017. A 100-Year Review: Total mixed ration feeding of dairy cows. J. Dairy Sci. 100:10143-10150. https://doi.org/ $10.3168 /$ jds.2017-12967.

Severson, D. 2019. Quick test for TMR dry matter. Accessed Mar. 17, 2021. https://sites.udel.edu/canr-animalscience/2019/02/12/ quick-test-for-tmr-dry-matter/.

Shenk, J. S. 1977. The role of plant breeding in improving the nutritive value of forages. J. Dairy Sci. 60:300-305. https://doi.org/10 .3168/jds.S0022-0302(77)83869-1.
Shenk, J. S., and M. O. Westerhaus. 1989. Optical instrument calibration system. U.S. Patent 4866644.

Shenk, J. S., and M. O. Westerhaus. 1991a. New standardization and calibration procedure for NIRS analytical systems. Crop Sci. 31:1694-1696. https://doi.org/10.2135/cropsci1991 .0011183 X003100060064x.

Shenk, J. S., and M. O. Westerhaus. 1991b. Population structuring of near infrared spectra and modified partial least squares regression. Crop Sci. 31:1548-1555. https://doi.org/10.2135/cropsci1991 .0011183 X003100060034x

Shenk, J. S., and M. O. Westerhaus. 1996. Calibration the ISI way. Pages 198-202 in Near Infrared Spectroscopy: The Future Waves. A. M. D. Davies and P. Williams, ed. NIR Publications.

Shenk, J. S., J. J. Workman, and M. O. Westerhaus. 2001. Application of NIR Spectroscopy to Agricultural Products. Handbook of Near Infrared Analysis. Practical Spectroscopy Series, Vol. 27, second ed. D. A. Burns and E. W. Ciurczak, ed. Marcel Dekker.

Soldado, A., B. De la Roza-Delgado, A. Martínez-Fernández, F. Vicente-Mainar, L. López, and E. Díaz-Bueno. 2009. Predicción de la composición bromatológica en dietas completas: clonación de instrumentos y transferencia de ecuaciones NIR en producto intacto. Tomo I: $340-342$ in XIII Jornadas sobre Producción Animal. AIDA. Zaragoza, Spain. Accessed Mar. 3, 2021. https://www .aida-itea.org/aida-itea/files/jornadas/2009/comunicaciones/2009 _NyA_44.pdf.

Soldado, A., O. Fernández, A. Martínez, and B. de la Roza-Delgado. 2003. Estudio comparativo de métodos analíticos para la determinación del contenido en almidón en ensilados de maíz. Pages 297-302 in Proceedings XLIII Reunión Científica de la SEEP. Granada, Spain. Spanish Society for the Study of Pastures.

Sørensen, L. K. 2004. Prediction of fermentation parameters in grass and corn silage by near infrared spectroscopy. J. Dairy Sci. 87:3826-3835. https://doi.org/10.3168/jds.S0022-0302(04)73522 -5 .

Sova, A. D., S. J. LeBlanc, B. W. Mcbride, and T. J. Devries. 2014. Accuracy and precision of total mixed rations fed on commercial dairy farms. J. Dairy Sci. 97:562-571. https://doi.org/10.3168/jds .2013-6951.

Thomson, A. L., D. J. Humphries, C. Rymer, J. E. Archer, N. W. Grant, and C. K. Reynolds. 2018. Assessing the accuracy of current near infra-red reflectance spectroscopy analysis for fresh grass-clover mixture silages and development of new equations for this purpose. Anim. Feed Sci. Technol. 239:94-106. https://doi .org/10.1016/j.anifeedsci.2018.03.009.

Van Soest, P. J., J. B. Robertson, and B. Lewis. 1991. Methods for dietary fiber, neutral detergent fiber, and nonstarch polysaccharides in relation to animal nutrition. J. Dairy Sci. 74:3583-3597. https:/ /doi.org/10.3168/jds.S0022-0302(91)78551-2.

Weiss, W. P., and N. R. St-Pierre. 2009. Impact and management of variability in feed and diet composition. Pages 83-96 in Tri-State Dairy Nutrition Conf. Proc. Michigan State University.

Williams, P. C., and D. Sobering. 1996. How do we do it: A brief summary of the methods we use in developing near infrared calibrations. Pages 185-188 in Near Infrared Spectroscopy: The Future Waves. A. M. C. Davies and P. C. Williams, ed. NIR Publications.

Yan, H., and H. W. Siesler. 2018. Hand-held near-infrared spectrometers: State-of-the-art instrumentation and practical applications. NIR News 29:8-12. https://doi.org/10.1177/0960336018796391.

Zamora-Rojas, E., D. Pérez-Marín, E. De Pedro-Sanz, J. E. GuerreroGinel, and A. Garrido-Varo. 2012. Handheld NIRS analysis for routine meat quality control: Database transfer from at-line instruments. Chemom. Intell. Lab. Syst. 114:30-35. https://doi.org/10 .1016/j.chemolab.2012.02.001. 